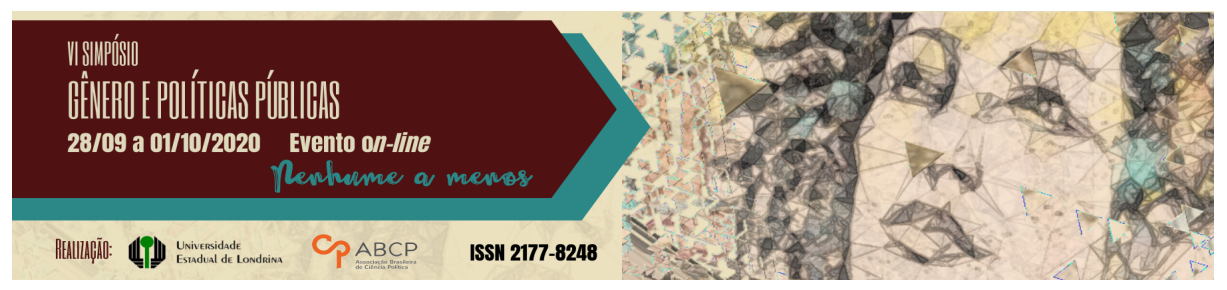

\title{
"O novíssimo testamento": o protagonismo feminino nas narrativas mitológicas na contemporaneidade
}

\author{
Vanda Fortuna Serafim ${ }^{1}$
}

\begin{abstract}
Resumo
O presente artigo analisa o filme "O novíssimo testamento" (2014) dirigido e produzido pelo belga Jaco van Dormael. Na narrativa fílmica constrói-se um personagem Deus, alcoólatra e perverso, que teria criado o mundo não por amor, mas por tédio, tendo escolhido a Bélgica como local para sua criação. $\mathrm{O}$ filme abre espaço para pensarmos a interferência da instituição religiosa e dos movimentos religiosos nas relações sociais, afetivas e de gênero ao constituirse como um convite à reflexão sobre a contribuição do cristianismo para organização de um sistema patriarcal fundamentado da destruição dos antigos deuses e deusas.
\end{abstract}

Palavras-chave: narrativas mitológicas; Deusa; feminino.

\section{"The brand new testament ": female protagonism in contemporary mythological narratives}

\begin{abstract}
This article analyzes the film "The brand new testament" (2014) directed and produced by the Belgian Jaco van Dormael. In the movie, God is alcoholic and perverse, he created the world not out of love, but out of boredom, he choose Belgium as the place for his creation. The movie opens space for us to think about the interference of the religious institution and religious movements in social, affective and gender relations. And the story is an invitation to reflect on the contribution of Christianity to the organization of a patriarchal system based on the destruction of the ancient gods and goddes.
\end{abstract}

11 Doutora em História pela UFSC. Professora adjunta no Departamento de História da Universidade Estadual de Maringá e no Programa de Pós-graduação em História (PPH/UEM). E-mail: vandaserafim@gmail.com

GT 10 - Gênero e religiosidades 
Keywords: mythological narratives; Goddess; female.

O presente artigo analisa o filme "O novíssimo testamento" (2014) dirigido e produzido pelo belga Jaco van Dormael. Na narrativa fílmica constrói-se um personagem Deus, alcoólatra e perverso, que teria criado o mundo não por amor, mas por tédio, tendo escolhido a Bélgica como local para sua criação. $O$ filme abre espaço para pensarmos a interferência da instituição religiosa e dos movimentos religiosos nas relações sociais, afetivas e de gênero ao constituir-se como um convite à reflexão sobre a contribuição do cristianismo para organização de um sistema patriarcal fundamentado da destruição dos antigos deuses e deusas. Tanto que o protagonismo do filme é desempenhado por Ea, sua filha pré-adolescente, com um estilo clichêgótico, que se rebela diante do descaso e sadismo do pai em relação aos seres humanos e a forma como ele instaurara o caos no mundo. A escolha do nome da personagem não é aleatória, Ea ou Enki refere-se ao deus babilônico da sabedoria e das águas, e responsável pela ordem no mundo.

O objetivo dessa comunicação é historicizar o contexto da produção da narrativa fílmica atentando a leitura que privilegia o empoderamento feminino, priorizando a figura a mãe, em detrimento do pai; assim como a filha em detrimento do filho. Para tanto, parte-se metodologicamente das discussões realizadas por Marco Napolitano acerca do cinema como fonte histórica e teoricamente dialoga-se com Roy Willis e Mircea Eliade a fim de pensar as atualizações mitológicas por meio do cinema.

Ao se partir de uma obra fílmica enquanto fonte histórica há certamente de se considerar que esta é, sem dúvidas, portadora de uma tensão entre evidência e representação. Nesse sentido é importante atentar à suas estruturas internas de linguagem e seus mecanismos de representação da realidade, analisando, a partir daí sua condição de "testemunho" de uma dada experiência histórica e social. Visa-se, 
portanto, empreender dois tipos de decodificação: a de natureza técnico-estética e a de natureza representacional, a primeira ligada à linguagem técnico-estética do cinema e a segunda, à realidade histórica ou social nela contidas, como alerta Marco Napolitano.

As considerações possíveis levantadas a partir da pesquisa apontam para forma como as conquistas históricas femininas tem colocado em cheque as narrativas sobre um Pai Criador e buscado reivindicar o papel da Grande Mãe na organização do mundo e no processo de criação, não por acaso, a trilha sonora do filme foi elaborada An Pierlé traz marcas visíveis desse rompimento "Deus, eu estou pegando a estrada longe do meu pai amargo a quem eu temo [...] Eu prefiro queimar minhas asas para amar do que viver no escuro e nunca ver a luz do dia!". Desse modo, acreditamos contribuir com a discussão acerca da presença de princípios e valores religiosos nas diferentes e diversas relações sociais e afetivas que se estabelecem em nossa sociedade.

\section{A narrativa fílmica}

O presente artigo analisa filme $O$ novíssimo testamento (2014) dirigido e produzido pelo belga Jaco van Dormael. Ao se partir de uma obra fílmica enquanto fonte histórica há certamente de se considerar que esta é, sem dúvidas, portadora de uma tensão entre evidência e representação. Nesse sentido é importante atentar à suas estruturas internas de linguagem e seus mecanismos de representação da realidade, analisando, a partir daí sua condição de "testemunho" de uma dada experiência histórica e social. Visa-se, portanto, empreender dois tipos de decodificação: a de natureza técnico-estética e a de natureza representacional, a primeira ligada à linguagem técnicoestética do cinema e a segunda, à realidade histórica ou social nela contidas (NAPOLITANO, 2006).

$O$ novíssimo testamento, classificado como gênero comédia/fantasia, trata-se de uma coprodução entre a Bélgica, a 
França e Luxemburgo. O filme foi produzido em suporte fílmico digital pela companhia Terra Incognita Films e distribuído pela Le Pacte, com tempo de execução 113 minutos. A trilha sonora do filme foi elaborada An Pierlé e o roteiro contou com Thomas Gunzig, além do próprio diretor. Foi lançado originalmente em 17 de maio de 2015 (Cannes) e em 01 de setembro de 2015 na Bélgica, além de ter sido préselecionado entre os nove finalistas para disputar o Oscar de melhor filme estrangeiro, mas não indo, infelizmente à disputa.

Orçado em 8,7 milhões de euros, o filme faturou em bilheteria 154 milhões de euros. O filme foi lançado nos cinemas brasileiros em 21 de janeiro de 2016. O elenco do filme contou com Benoît Poelvoorde (Deus), Catherine Deneuve (Martine), François Damiens (François), Yolande Moreau (esposa de Deus), Pili Groyne (a filha de Deus, Ea), Laura Verlinden (Aurélie), Serge Larivière (Marc), David Murgia (Jesus Christ), Johan Leysen (esposo de Martine), Pascal Duquenne (Georges), Viviane De Muynck (mãe de Georges) e Johan Heldenbergh (padre).

O filme foi indicado, em diversas categorias, para festivais de cinema, tendo vencido como melhor filme no Belgian Film Critics Association, como maior audiência na Eupora e melhor filme no Biografilm Festival, melhor designer de produção no European Film Awards, melhor comédia no Fantastic Fest, levou o Prêmio Fedeora de melhor filme internacional no Haifa International Film Festival, o melhor filme em coprodução no Luxembourg Film Awards, melhor filme, diretor, trilha sonora original e roteiro no Magritte Awards, melhor filme fantástico europeu no Méliès d'Or, prêmio de audiência e especial do júri no Norwegian International Film Festival e de melhor atriz e melhor filme fantástico europeu no Sitges Film Festival.

O diretor Jaco Van Dormael ${ }^{2}$ (63 anos), nascido em Ixelles,

2 Informações sobre o diretor disponíveis em: http:/ / www.theinfolist.com/php/SummaryGet.php?FindGo=Jaco\%20van\%20Dorma el . Acesso: 28/08/2016 e http://cinemajam.com/mag/interviews/jaco-van-dormael Acesso: 20 ago. 2016. 
Bélgica em 1957, tem atuado, desde os inícios de 1980, também como roteirista, dramaturgo, produtor e diretor de fotografia. Com temas sempre tratados de forma complexa, seus filmes são aclamados pela crítica e especialmente reconhecidos pela forma respeitosa e solidária que são retratadas as pessoas com deficiências físicas e mentais. Essa sensibilidade aparece na fonte que analisamos na construção do personagem Aurélie, que na infância tivera o braço amputado, passando a usar uma prótese.

Jaco Van Dormael foi criado na Alemanha até sete anos de idade, quando sua família retornou à Bélgica. Em seu nascimento, ele quase foi estrangulado pelo cordão umbilical e recebeu fornecimento insuficiente de oxigênio, gerando medo de que isso lhe causasse lesões e danos no desenvolvimento mental. Isto talvez explique porque os mundos de pessoas com deficiências físicas e mentais são recorrentemente explorados em seus temas.

Marcam sua trajetória o prazer em trabalhar com crianças, tendo sido, inclusive, palhaço de circo por um certo tempo, antes de desenvolver interesse por cinema e ingressar no Institut national supérieur des arts du spectacle et des techniques de diffusion (INSAS) e depois no Louis Lumière College, em Paris. Brincadeiras infantis, infância e inocência se tornaria fortes temas ao longo de sua obra.

Na década de 1980, Van Dormael produziu uma série de curtas-metragens que despertaram interesse crítico considerável. Dentre eles Maedeli la brèche (1981); Stade 81 (1982) Les voisins (1981), L'imitateur (1982), Sortie de secours (1983) e De boot (1985). Seu mais famoso curta do período é È pericoloso sporgersi (1984), que ganhou o Grand Prix na competição internacional no Festival Internacional de Curtas de Clermont-Ferrand. Como diretor, suas principais longasmetragens são Um homem com duas vidas (1991), O oitavo dia (1996), Mr. Nobody (2009) e O novíssimo testamento (2015). Sendo que o penúltimo foi o unico gravado em inglês, uma língua não belga, e que o projetou internacionalmente. 
Sobre as temáticas exploradas por Van Dormael, há quase sempre o uso distintivo da narrativa ingênua e a análise do mundo de uma perspectiva inocente. Os pontos de vista dos personagens são muitas vezes coloridos, imaginativos, e um pouco distantes da realidade, com ligeiros elementos do imaginário surreal usados para ilustrar suas imaginações ativas.

Seus filmes também costumam terminar com uma morte, que é retratada não como uma tragédia, mas como movido prazeroso no qual o falecido olha feliz para o mundo abaixo. Entre o Céu e a Terra terminam com um nascimento, que é semelhante a uma passagem do personagem para um novo mundo, transmitindo uma sensação melancólica de felicidade. Van Dormael faz uso proeminente de músicas de padrões nostálgicos e todos os filmes de Van Dormael contém elementos surreais. $\mathrm{O}$ uso de personagens com deficiência, retratados cuidadosamente e a ênfase nas características infantis também marcam o trabalho do diretor.

\section{O novíssimo testamento}

Deus, alcoólatra e perverso, criou o mundo não por amor, mas por tédio. Essa é uma das premissas do filme que abrem uma série de reflexões sobre a relação entre deuses e humanos, deuses e deuses e humanos e humanos. Ele vive na Bélgica com sua esposa, passiva e quase sem voz e Ea, sua filha pré-adolescente, com um estilo clichêgótico de rebeldia, entediada com a vida dos pais e a íntima relação com a televisão.

O pai, Deus, teria criado o mundo em seu escritório, um cômodo da casa, sempre trancado, rodeado por arquivos com os dados dos seres humanos e no centro dele, uma mesa, com um computador, bastante antigo, branco, um modelo da década de 90, embora o filme se passe na contemporaneidade. Deus criou o mundo como nós conhecemos a partir de Bruxelas, mas essa não foi sua primeira tentativa. Anteriormente as criaturas divinas que habitariam nosso 
mundo eram os animais, girafas e leões assistindo TVs e dirigindo carros. Descontente, Deus cria o homem e sente-se satisfeito com a criação, cujo primeiro ato é a alegria com a descoberta do próprio pênis. O filme abre espaço para uma série de discussões, como sexualidade, feminismo, autoritarismo, entre tantos outros. Para finalidade desta discussão nos centraremos nos evangelhos que subdividem as sequencias do filme.

Convém, todavia, destacar que o enigma de como o mundo veio a existir é um problema central para todas as mitologias.

Às vezes, o início de todas as coisas é descrito como um vazio ou vácuo total, ou alternativamente como uma vastidão ilimitada de água, um ermo indiferenciado envolto em escuridão - uma idéia comum às narrativas míticas do Oriente Médio, dos povos khoisan do sul da África e de muitas tradições da América do Norte e do Sudeste Asiático. No entanto, a imagem da criação mais amplamente disseminada representa o universo primitivo na forma de um ovo, contendo a potencialidade de tudo em sua casca plenamente envolvente. $O$ padrão usual é que deve ocorrer algum tipo de ação que inicia um processo de mudança e desenvolvimento. Para o povo dogon, da África Ocidental, uma vibração desencadeada por Amma, o deus criador, rompeu os limites do ovo cósmico e libertou as divindades opostas da ordem e do caos. O ermo das águas descrito pelos cheyennes da América do Norte foi redimido por meio dos esforços da humilde gaivota aquática, que com seu bico salvou das profundezas um punhado de lama, o qual foi então transformado pelo Espírito de Tudo em terra seca. Uma história similar de pássaro prestativo, no caso a andorinha, na formação da primeira terra é contada nas ilhas do Sudeste Asiático. E no mito egípcio, o ato primordial da criação foi o surgimento de um outeiro com terra do abismo aquoso chamado Nun. (WILLIS, 2007. p.18).

Após ter descoberto que o pai controla o mundo pelo seu 
computador como uma forma de diversão, ou seja, criando uma série de leis para criar transtornos e estresses entre os humanos, atribuindo angustias e sofrimentos por puro sadismo e prejudicando as pessoas por escárnio, Ea, que se incomoda com as atitudes do pai recorre ao irmão J.C. (Jesus Cristo) para saber como fugir de casa e modificar tudo aquilo. Identificamos aqui, o primeiro ato de transgressão.

As transgressões são entendidas por Roy Willis (2018) como infrações na ordem tida como natural.

Muitos mitos gregos falam sobre transgressores e seu castigo. Essas histórias podem ter sido contadas para ajudar a manter a ordem adequada das coisas, especialmente no seio da família, pois muitos mitos envolvem ultrapassar os limites da propriedade sexual. Quase todos têm protagonistas humanos, porque os deuses e as deusas geralmente podiam ter comportamento inadequado impunemente, enquanto os erros dos mortais eram habitualmente punidos com severidade - um paradoxo do qual os gregos antigos tinham consciência (WILLIS, 2007. p. 18).

O filme é narrado em primeira pessoa, na perspectiva de Ea que tenta descobrir um mundo diferente do seu e transformá-lo. Vemos aqui o que Roy Willis denominou as origens do infortúnio:

Independentemente de o mundo ter passado a existir por acidente ou desígnio, uma vez criado ele é visto em todas as mitologias como passível de mudança arbitrária. A causa de eventos imprevisíveis muitas vezes é imputada ao capricho de divindades aparentemente motivadas por emoções tão humanas quanto desejo sexual, raiva ou ciúme. No mito egípcio, o violento deus Seth criou devastação na terra assassinando seu irmão Osíris, de cuja alta reputação ele parecia ter ciúme. O rancor da deusa grega Éris ("disputa"), ofendida porque Zeus não a convidou para o casamento da ninfa do mar Tétis com o mortal Peleu, leva indiretamente à Guerra de Tróia. Na história da guerra, uma complicada série de eventos nos quais 
os protagonistas são seres divinos impelidos por motivos vis leva a grandes sofrimentos humanos e perda de vidas. A mitologia grega passa uma mensagem semelhante em seu relato de como o mal, na forma de doença e morte, veio ao mundo originalmente. Mais uma vez, esse desastre para a humanidade é visto aqui como o resultado de uma longa luta entre seres sobrenaturais (nesse caso, Prometeu e Zeus). O mito também explica a criação da primeira mulher, Pandora, como um estratagema de Zeus para ficar quites na briga com Prometeu. Enviada com um jarro selado (ou "caixa") ao irmão de Prometeu, Epimeteu, que a apresenta à sociedade humana, ela abre o jarro fatal por curiosidade, soltando no mundo seu calamitoso conteúdo de males, incluindo todo tipo de doenças; apenas a esperança permanece dentro do jarro. No decorrer desse mito, Prometeu aparece como o iniciador da civilização humana (WILLIS, 2007. p. 22).

Ea é a transgressora e causadora do infortúnio. A postura de indignação/complacência com a mãe e repúdio do pai são evidentes. Seguindo os conselhos do irmão, EA rouba seis fichas aleatórias no arquivo de Deus para encontrar seus novos apóstolos, dando continuidade à obra do irmão. No filme, a organização do mundo é aleatória, sem interligações ou providencialismos, organizando-se pela simples vontade de Deus em extravasar suas frustrações se divertindo com os humanos. A forma que ela encontra de anular o poder do pai é enviando por mensagem de texto a data e hora exata da morte de cada pessoa. Assim, cada um passa a saber exatamente quanto tempo possui de vida, o que modifica em partes as ações, preocupações e pensamentos humanos.

A trama se divide em nove momentos, "Gênesis", o início, onde é apresentado a processo de criação do mundo. "Êxodo" que narra como ao descobrir as maldades do pai, Ea envia aos seres humanos a data de suas respectivas mortes. Pela máquina de lavar, Ea foge da casa do pai e chega ao mundo dos humanos. Logo encontra um morador de rua que ficaria encarregado de narrar a estória de cada 
apóstolo. Embora uma deusa, Ea tem poucos poderes, pois ainda não aprendeu com usá-los, seu principal dom é conhecer a música de dentro de cada pessoa, ao aproximar o ouvido de seu coração. Dessa maneira, Ea conhece as pessoas por dentro, pelo que possuem de mais íntimo e o que por vezes são incapazes de reconhecer.

Para estes dois primeiros momentos talvez seja coerente as reflexões de Henri Bergson na obra O riso.

Que significa o riso? Que haverá no fundo do risível? Que haverá de comum entre uma careta de bufão, um trocadilho, um quadro de teatro burlesco e uma cena de fina comédia? Que destilação nos dará a essência, sempre a mesma, da qual tantos produtos variados retiram ou o odor indiscreto ou o delicado perfume? Os maiores pensadores, desde Aristóteles, aplicaram-se a esse pequeno problema, que sempre se furta ao empenho, se esquiva, escapa, e de novo se apresenta como impertinente desafio lançado à especulação filosófica (BERGSON, 1987, p. 1).

Mais do que definição a fantasia cômica, O novíssimo testamento traz antes de tudo, algo de vivo. Ainda que, a seu modo, até nos seus maiores desvios, metódico em sua insensatez, fantasiando, e evocando em sonho visões compreendidas por uma sociedade inteira, "acaso a fantasia cômica não nos informará sobre os processos de trabalho da imaginação humana, e mais particularmente da imaginação social, coletiva, popular? Fruto da vida real, aparentada à arte, acaso não dirá nada sobre a arte e a vida?" (BERGSON, 1987, p. 1).

Para Bergson o riso refere-se menos ao cômico propriamente que ao lugar onde devemos buscá-lo: o humano. Ver Deus à imagem e semelhança do homem que criou, em não necessariamente em seus melhores aspectos, ressalta a ideia de que não há comicidade fora do que é propriamente humano. Ao ir para o mundo atrás de Ea, os poderes de Deus são anulados, ele é um simples humano que para os demais, pensa que é Deus. Já não onipotente, onisciente e onipresente. É fraco, franzino, estúpido, arrogante e prepotente. Suas continuas 
tentativas de ser Deus sendo homem geram o riso e demonstram a "insensibilidade", assinalada por Bergson que naturalmente acompanha o riso. Nos divertimos com a desgraça de Deus, uma vez que ele seria responsável pelas nossas desgraças.

Mas esse riso se dá em cumplicidade, com Ea, com J.C e com a esposa de Deus. "Não desfrutaríamos o cômico se nos sentíssemos isolados" (BERGSON, 1987, p. 2). Tratando de um filme a ser exibido a um público, sabe-se que riso do espectador, no teatro, é tanto maior quanto mais cheia esteja a sala. Mas seriam os efeitos cômicos são traduzíveis de uma língua para outra, relativos, pois, aos costumes e às ideias de certa sociedade?

É interessante observar que a maior parte da premiação que o filme recebeu foi na Europa. Nos EUA, embora tenha participado de uma pré-seleção para concorrer ao Oscar de melhor filme estrangeiro, não chegou às vias de fato. Seria o expectador norte-americano menos inclinado a rir das desgraças de Deus? Ou da prepotência de pensar-se Deus sem sê-lo. O riso deve corresponder a certas exigências da vida em comum e deve ter uma significação social. As reflexões de Henri Bergson elucidam os evangelhos segundo os apóstolos de Ea: Aurélie, Jean-Claude, o obcecado sexual, o assassino, Martine e Willy.

\section{A recriação do mundo}

"A canção das canções" é a última parte do filme, mas instaura também um novo início. A narrativa final do filme se inicia com mãe de Ea limpando a casa feliz e enfeitada com flores, após a filha conseguir mais seis apóstolos, totalizando 18, seu número preferido, como o número de jogadores de baseball. Ao limpar o escritório do marido ela retira, para ligar o aspirador, o fio do computador da tomada. É domingo. Todos estão na praia sentados em volta de Willy, que aguarda sua morte. Aquele seria seu último dia. Um avião começa a perder a altitude em direção à praia. Deus está dentro dele e se apavora. A mãe coloca a tomada do computador de volta e a máquina 
lhe pergunta "quer reiniciar?", cautelosamente ela se aproxima e digita "sim", o computador pede a senha e ela digita " 18 ". Lê-se no computador: "Olá deusa, estou feliz em revê-la"! Ela sorri.

Sobre o culto a Grande Deusa, notamos desde o final do século XX um significativo revigoramento. Em 1974, em Minneapolis nos Estados Unidos, várias pessoas se reuniram para elaborar uma declaração contendo os princípios da crença Wicca, a religião da Grande Deusa, que atualmente reúne seguidores em todo mundo. Esse processo precisa ser compreendido em consonância com a preocupação cada mais maior com o destino do planeta, os movimentos ambientais e o reiterado discurso de destruição da natureza (ANDRADE et al, 2013)

Inana (Suméria), Nut (Egito), Freya (Nórdicos) e Afrodite (Grécia) são alguns exemplos de deusas relacionadas especialmente a fertilidade. As diversas representações da deusa mostram-na como portadora de um caráter forte, poderosa e dinâmica. Nesse sentido é interessante a construção da personagem feminina no decorrer do filme. Muda, passiva, insegura. Que em muito se afasta da forma como a imagem da deusa é representada na história das religiões, justamente em contraposição ao conceito equivocado de que o feminino é tranquilo, passivo ou inferior. A grande deusa está associada a vida que dá poderes, renovação, renascimento, transformação e com o mistério da morte (ANDRADE et al, 2013). É o que encontramos ao final da narrativa fílmica.

O termo rever é interessantíssimo, não é a primeira vez que ela tem acesso ao computador e a criação do mundo. A mulher subordinada e sem voz durante o filme recria o mundo. Elimina as previsões de morte e colore o céu com flores, retira a gravidade, permite que as pessoas caminhem no fundo do mar como se estivessem na terra. Ela olhando para cima emocionada grita "É minha mãe. É a mamãe". O mundo retorna a era da deusa Mãe.

Deus não é o todo poderoso, ele se quer tem poderes, não 
consegue fazer milagres. A sua autoridade está na manipulação por meio de um computador e na intervenção destrutora na vida das pessoas. Como um Deus assim se mantem no poder? Dentro de uma família patriarcal, onde a mãe, anteriormente Deusa, sofre abusos constantes e é silenciada. O filho, Jesus Cristo, tenta desafiar o pai, mas não se desvincula totalmente deste. É a filha, Ea, ocultada das narrativas que toma as dores da mãe, do irmão e de si mesmo, após ser espancada pelo pai pelo fato de questioná-lo, que subverte a ordem do pai. Ao instaurar ao caos, ela abre espaço para que a mãe reassuma o poder e se inicie uma nova era, mais colorida e leve.

\section{Referências}

ANDRADE, Solange Ramos; SERAFIM, Vanda Fortuna; Costa, Daniel Lula; Palamin, Flávio. História das Religiões. Maringá, Eduem: 2013.

BERGSON, Henri. O riso: ensaio sobre significações do cômico. 2. ed. Rio de Janeiro: Guanabara, 1987.

LE TOUT NOUVEAU TESTAMENT (O Novíssimo Testamento). Direção de Jaco van Dormael. Bélgica, a França e Luxemburgo. Produzido por Terra Incognita Films. 2014. 113 min.

NAPOLITANO, Marcos. A história depois do papel. In: PINSKY, Carla Bassanezi (Org.). Fontes Históricas. São Paulo: Contexto, 2006

WILLIS, Roy. (coord.) Mitologias. Deuses, heróis e xamãs nas tradições e lendas de todo o mundo. São Paulo: Publifolha, 2007. 